\title{
Power, Purpose, And Policy in The Time of COVID
}

\author{
Lucy M. Gowdie \\ Peninsula Grammar School
}

\begin{abstract}
While a darkness has descended upon societies around the globe, there exist glimmers of hope in the education sector to positively transform current practice. The situation confronting educators in 2021 has not abated, in fact, it has magnified, escalating to a point where the knowledge acquired in 2020 demands meaningful and urgent application in 2021. As a community of educators, we have a choice to make. Do we pivot towards pessimism or do we look to our purpose with renewed vigor and belief that even in the darkest of days there exists opportunity? Chief amongst the most pertinent lessons of 2020 was the necessity of consistency in communication and the purpose of effective policy in framing the new reality and in creating certainty for school communities. Adapted over the course of 2020 to meet the ever-changing social context of COVID, the process of designing policy, implementing, then assessing the effectiveness of it, albeit in a remote context, presented new and complex challenges for education leaders. This presentation will provide tangible policy provisions, templates, and leadership guidance for application of three critical policies in a K-12 context: Student Wellbeing; Working from home and Crisis Management (The Chain of Command) The afore mentioned policies were developed through the lived experience of school leaders, the varied emotional responses of families and the behaviour of staff and students through mid to late 2020. The urgent and elongated nature of this crisis meant policy adaptions had to be made quickly and their effectiveness measured consistently to ensure that learning, the core business of every educational institution, remained the work.
\end{abstract}

Keywords: educational leadership; learning; policy; teaching; community 